\title{
Effects of ENSO on weather-type frequencies and properties at New Orleans, Louisiana, USA
}

\author{
Gregory J. McCabe ${ }^{1, *}$, Robert A. Muller ${ }^{2}$ \\ ${ }^{1}$ US Geological Survey, Denver Federal Center, MS 412, Denver, Colerado 80225, USA \\ ${ }^{2}$ Southern Regional Climate Center, Department of Geography and Anthropology, Louisiana State University, Baton Rouge, \\ Louisiana 70803, USA
}

\begin{abstract}
Examination of historical climate records indicates a significant relation between the El Niño/Southern Oscillation (ENSO) and seasonal temperature and precipitation in Louisiana. In this study, a 40 yr record of twice daily (06:00 and 15:00 h local time) weather types are used to study the effects of ENSO variability on the local climate at New Orleans, Louisiana. Tropical Pacific seasurface temperatures (SSTs) for the NINO3.4 region are used to define ENSO events (i.e. El Niño and La Niña events), and daily precipitation and temperature data for New Orleans are used to define weather-type precipitation and temperature properties. Data for winters (December through February) 1962-2000 are analyzed. The 39 winters are divided into 3 categories; winters with NINO3.4 SST anomalies $<-1^{\circ} \mathrm{C}$ (La Niña events), winters with NINO3.4 anomalies $>1{ }^{\circ} \mathrm{C}$ (El Niño events), and neutral conditions (all other years). For each category, weather-type frequencies and properties (i.e. precipitation and temperature) are determined and analyzed. Results indicate that El Niño events primarily affect precipitation characteristics of weather types at New Orleans, whereas the effects of La Niña events are most apparent in weather-type frequencies. During El Niño events, precipitation for some of the weather types is greater than during neutral and La Niña conditions and is related to increased water vapor transport from the Tropics to the Gulf of Mexico. The changes in weather-type frequencies during La Niña events are indicative of a northward shift in storm tracks and/or a decrease in storm frequency in southern Louisiana.
\end{abstract}

KEY WORDS: El Niño $\cdot$ La Niña $\cdot$ Southern Oscillation · Weather types Resale or republication not permitted without written consent of the publisher

\section{INTRODUCTION}

Weather types are aggregate representations of a number of meteorological variables, and the frequencies and properties (e.g. temperature, precipitation) of weather types largely determine the climate of a place. Weather types have proven useful in numerous environmental studies and have been developed and applied in various regions of the world (Muller 1977, Yarnal 1993). Since 1961 a weather-type calendar has been maintained for New Orleans, Louisiana, which has been used to study various environmentally sensitive processes in southern Louisiana (Muller 1977,

*E-mail: gmccabe@usgs.gov
Muller \& Wax 1977, McCabe \& Muller 1986, Faiers 1988, Yarnal 1993).

The El Niño/Southern Oscillation (ENSO) is a primary mode of global climate variability and is related to temperature and precipitation anomalies for various regions around the world (Kiladis \& Diaz 1989). In general, ENSO effects are most apparent in North America during winter. One area where ENSO has a significant effect on climate is the Gulf Coast of the southern United States (Douglas \& Englehart 1981, Ropelewski \& Halpert 1986, Sittel 1994). Douglas \& Englehart (1981) found that for El Niño conditions, winter precipitation along the Gulf Coast was above average, and related this increase in winter precipitation to increased frontal activity over the Gulf of Mexico. Similarly, Ropelewski \& Halpert (1986) found that for El 
Niño events, winter precipitation in the southeastern US was above average and winter temperatures were below average. In contrast, during La Niña events, winter precipitation along the Gulf Coast is below average (Douglas \& Englehart 1981, Kiladis \& Diaz 1989). For example, 5 of the 7 driest winters at New Orleans between 1962 and 2000 were La Niña winters.

Previous studies have identified and quantified the relations between ENSO and climate for various locations through the world (Kiladis \& Diaz 1989). These studies, however, have not examined the local or regional weather patterns associated with these climate effects. The weather-type calendar for New Orleans provides an opportunity to examine the effects of ENSO on regional weather patterns that are linked with the observed ENSO-related changes in precipitation and temperature.

Since 1961 a weather-type calendar has been maintained for New Orleans, Louisiana. This unique data set offers an opportunity to examine effects of ENSO on the climate of southern Louisiana in a weather-type framework, thereby explaining the causes of ENSO relations with southern Louisiana temperature and precipitation. The objectives of this study are to (1) identify the effects of ENSO on Louisiana winter weather-type frequencies and properties, and (2) determine if the effects of ENSO on Louisiana winter climate are due to effects on weather-type frequencies, weather-type properties, or both.

\section{METHODS}

\subsection{Weather types}

The synoptic weather-type data set used in this investigation was initially developed by Muller (1977) for southern Louisiana. The typing is based on visual interpretation of the surface synoptic weather maps prepared by the Weather Bureau/National Weather Service (NWS), and identifies the dominant surface synoptic circulation that affects the weather at a particular place and time, in this case New Orleans at 06:00 and 15:00 h Central Standard Time (CST).

The Muller synoptic classification and the daily weather-type calendars are related to the classic daily synoptic calendars developed by Hess \& Brezowsky (1969) for central Europe and by Lamb (1972) for western Europe and the northern Atlantic Ocean, but this classification differs greatly from the classic European classifications in terms of geographical perspective and scale. The European classification types were for large geographical areas as much as $1000 \mathrm{~km}$ or more in cross-section. Therefore, for a given weather type, on a given day, the local and regional weather varied greatly across a weather map. In the Muller classification, by contrast, the perspective and weather typing relate directly to a region (e.g. in and around New Orleans), and the daily weather typing rather closely represents day-to-day weather and climate events in the region. Hence, the weather-type calendars are representative of weather and climate properties and variability as well as environmental impacts on daily-toseasonal time scales.

The 8 Muller weather types were divided into 5 fair and 3 stormy types (Fig. 1). A brief description of each weather type follows:

\subsubsection{Fair weather types}

Continental High $(\mathrm{CH})$ conditions are associated with fair weather corresponding to a core of high pressure following a Canadian cold front. This type of weather exhibits cool and dry properties with north or northeast winds across southern Louisiana.

Pacific High $(\mathrm{PH})$ weather brings mild and relatively dry air into southern Louisiana following a Pacific cold front. Normally this weather type is accompanied by fair and mild weather with west to northwest winds.

Gulf High $(\mathrm{GH})$ situations result when polar highs push southward over eastern Texas or Louisiana to the Gulf of Mexico in winter, or when the Bermuda High extends far to the southwestern US in summer and fall, producing southwesterly winds over Louisiana. Depending upon the season, this flow normally consists of maritime tropical or continental tropical air.

Coastal Return (CR) weather develops when the crest of a high-pressure ridge drifts to the east of Louisiana and surface winds veer from northeast to east to southeast. This weather type exhibits fair and mild weather in winter and spring and fair but warm and humid weather in summer and early fall.

Gulf Return (GR) situations occur when a highpressure ridge drifts far to the east of Louisiana. The surface pressure pattern on the back side of the high results in a flow of warm and moist air from the Caribbean Sea and the Gulf of Mexico. Winds from the southeast and south generally accompany this weather type.

\subsubsection{Stormy weather types}

Frontal Overrunning (FOR) weather occurs in the cool sector behind a cold front or ahead of a warm front, and it is generally cloudy and associated with precipitation and with winds mostly from the northeast. This situation often occurs when fronts become quasi-stationary along the Gulf Coast or over the west- 
Continental High

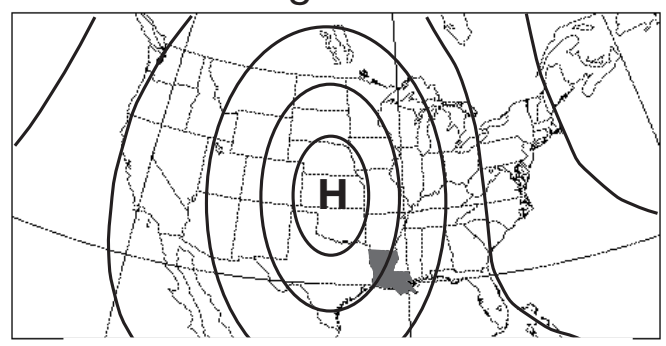

\section{Gulf High}

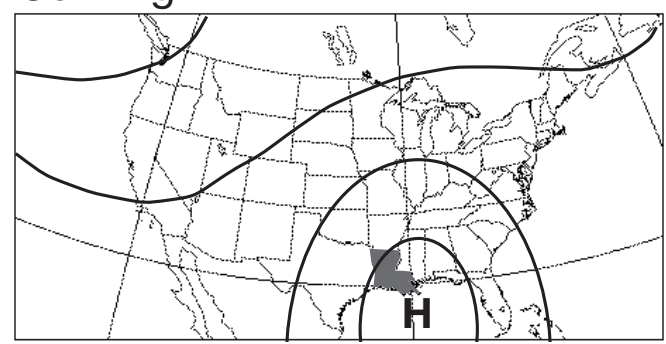

\section{Gulf Return}

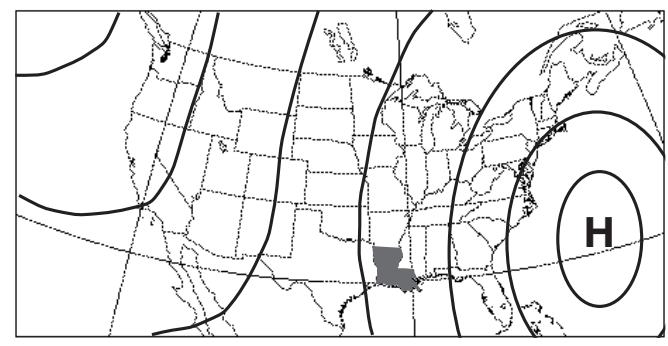

\section{Frontal Overrunning}

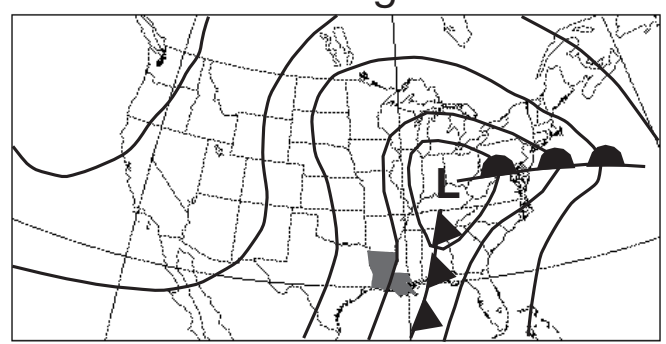

Pacific High

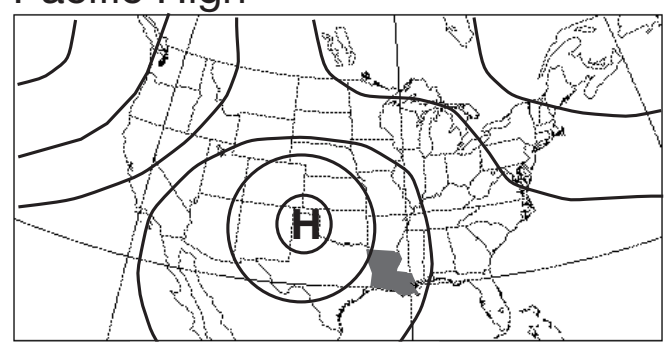

\section{Coastal Return}

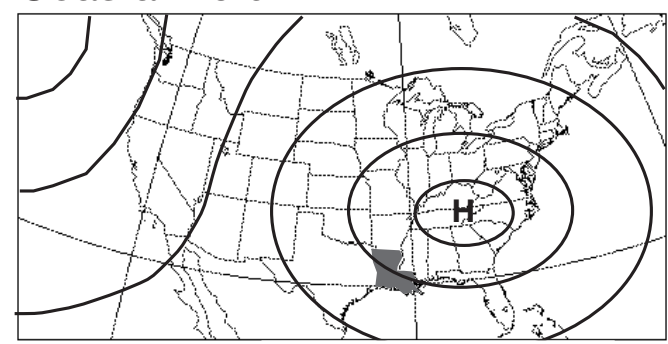

Frontal Gulf Return

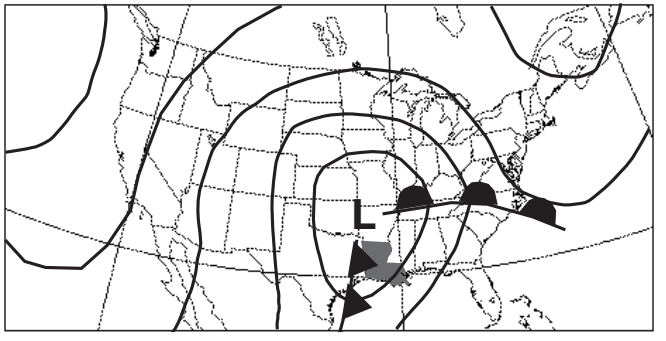

Gulf Tropical Disturbance

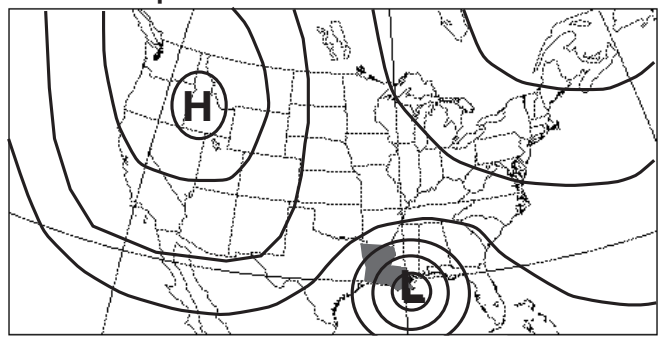

Fig. 1. Idealized examples of sea-level pressure patterns associated with the 8 Muller weather types. Louisiana is shaded

ern Gulf of Mexico. Waves often develop along the front and then sweep northeastward, bringing thick clouds and precipitation.

Frontal Gulf Return (FGR) weather occurs in the warm sector ahead of an approaching cold front or following the passage of a warm front. Winds are typically from the southwest and include moisture from the Gulf of Mexico. The weather becomes increasingly turbulent, owing to instability, lifting, and convergence along the frontal boundary, and precipitation often results. At times, thunderstorms, squall lines, and occasional severe weather accompany this weather type.

Gulf Tropical Disturbance (GTD) involves tropical systems that develop over the Gulf of Mexico or the Caribbean Sea and usually drift east to west across the northern Gulf. These systems range from relatively weak easterly waves to severe hurricanes, and they occur in summer and fall. 


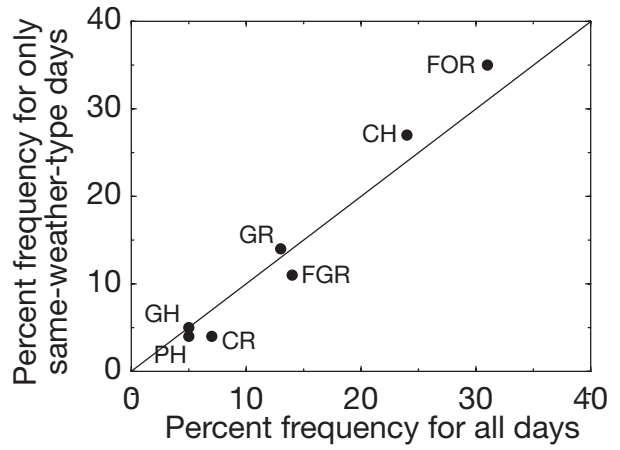

Fig. 2. Comparison of winter (December-February) weathertype frequencies for all days, with the frequencies for days with the same weather-type designation for both observation periods. CH: Continental High; PH: Pacific High; GH: Gulf High; CR: Coastal Return; GR: Gulf Return; FGR: Frontal Gulf Return; FOR: Frontal Overrunning

\subsection{Weather-type frequencies and properties}

For this study, weather-type calendars for winters (December through February) from December 1961 to February 2000 were used (39 winters). The most frequent weather types during the winter season are FOR and $\mathrm{CH}$ (Fig. 2). These 2 weather types are present for over $50 \%$ of the days in southern Louisiana during winter. In addition to being the most frequently occurring winter weather types, FOR and $\mathrm{CH}$ weather also are the most persistent weather types. The next most frequent winter weather types are GR and FGR. CR, $\mathrm{GH}$, and $\mathrm{PH}$ weather occur much less frequently during winter than do the other weather types, except for GTD weather which does not occur at all during winter. Because GTD weather does not occur during winter, it will not be discussed in this paper.

Because the weather-type calendar includes weather-type designations for 06:00 and 15:00 h CST, there are many days in the record with different weather-type designations for the 2 time periods. To compute reliable temperature and precipitation properties for each weather type, only days with the same weather-type designation for both time periods were used. This sub-setting of the data resulted in $2144 \mathrm{~d}$ for analysis, and a loss of $39 \%$ of the days from the complete data set. To ensure an appropriate analysis of weather-type frequencies, it is important that the weather-type frequencies for the subset of data are similar to those computed from the entire data set (Fig. 2). To determine if the weather-type frequencies for the subset data were similar to those from the entire data set, a Kolmogorov-Smirnov test was performed comparing the 2 frequency distributions (Blalock 1979, Conover 1980). The results of the KolmogorovSmirnov test indicated that there is no significant difference between the 2 frequency distributions.
Of the 7 weather types that occur during winter, precipitation rates are highest for FGR and FOR weather, whereas precipitation rates are lowest for $\mathrm{CH}, \mathrm{PH}, \mathrm{GH}$, and CR weather (Fig. 3). The warmest weather types on average are GR and FGR, and the coolest are $\mathrm{CH}$ and FOR (Fig. 3). Because the weather types have different temperature and precipitation properties, the frequency of these weather types during a season have significant effects on the weather in southern Louisiana (Muller 1977, McCabe \& Muller 1986).

\subsection{Precipitation and temperature data}

Daily temperature and precipitation data observed at New Orleans International Airport near New Orleans (Fig. 4) are used to determine weather-type temperature and precipitation properties for El Niño, La Niña, and neutral conditions. The daily precipitation data are $24 \mathrm{~h}$ sums of hourly precipitation measurements, and the daily temperature data are averages computed from $24 \mathrm{~h}$ temperature observations. The daily precipitation and temperature data from New Orleans also are used to compute mean winter (December through February) temperature and precipitation for the years 1962-2000.

\subsection{ENSO index}

NINO3.4 sea-surface temperatures (SSTs) are used in this study to define El Niño and La Niña winters (Trenberth 1997, Gershunov \& Barnett 1998). The NINO3.4 SSTs have become increasingly popular as an index of ENSO (Trenberth 1997), as it has become apparent that the SSTs most involved in ENSO are in the central Pacific Ocean, not in the coastal water off of

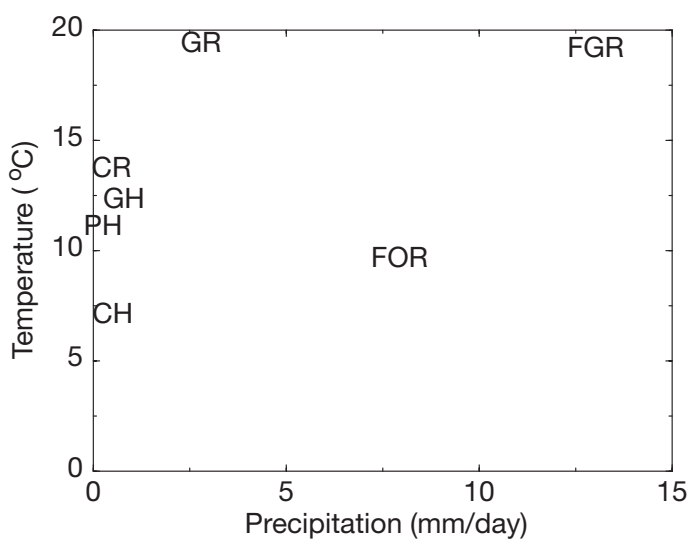

Fig. 3. Mean winter (December-February) precipitation and temperature properties for each weather type, 1962-2000 
Peru and Ecuador (Trenberth \& Hoar 1996). The NINO3.4 SST region extends from the eastern tropical Pacific Ocean to the central tropical Pacific and the index is computed as the average SST for the area $5^{\circ} \mathrm{S}-5^{\circ} \mathrm{N}, 120-170^{\circ} \mathrm{W}$ (Fig. 4). When NINO3.4 SST anomalies are positive, an El Niño exists, and when NINO3.4 SST anomalies are negative, a La Niña exists. Monthly NINO3.4 SST values were averaged to compute a time series of mean winter NINO3.4 SSTs for the years 1962-2000.

El Niño and La Niña years were determined as follows; winters with a mean NINO3.4 SST anomaly $>1^{\circ} \mathrm{C}$ were considered El Niño winters, and winters with a mean NINO3.4 SST anomaly $<-1^{\circ} \mathrm{C}$ were considered La Niña winters (Fig. 5). These rules resulted in 8 El Niño winters and 7 La Niña winters for the 39 winters analyzed.

\section{RESULTS AND DISCUSSION}

\subsection{Weather-type frequencies}

Table 1 illustrates the number of observations for each weather type and for each climate condition (i.e. El Niño, neutral, and La Niña events). Frequencies of each weather type were computed for each winter. To examine the effects of ENSO on weather-type frequencies, the distribution of weather-type frequencies for $\mathrm{El}$ Niño and La Niña winters were compared with the frequencies for neutral years (Fig. 6). For El Niño events, the changes in weather-type frequencies are small. For La Niña events, however, changes in weather-type frequencies for GR and FOR weather are significantly different (at a $95 \%$ confidence level, based on a Student's

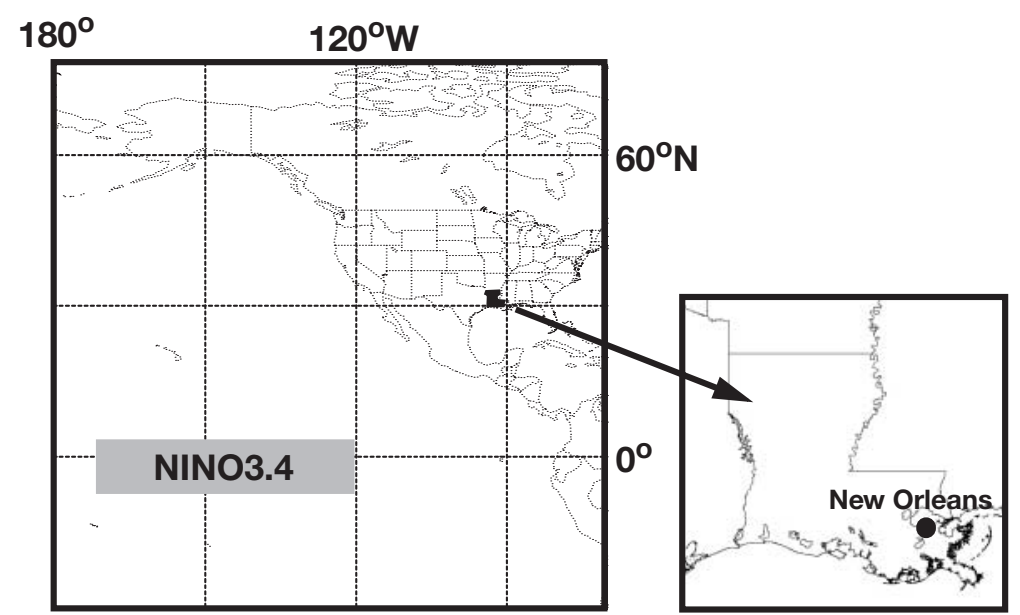

Fig. 4. Location maps indicating NINO3.4 sea-surface temperature region and New Orleans, Louisiana

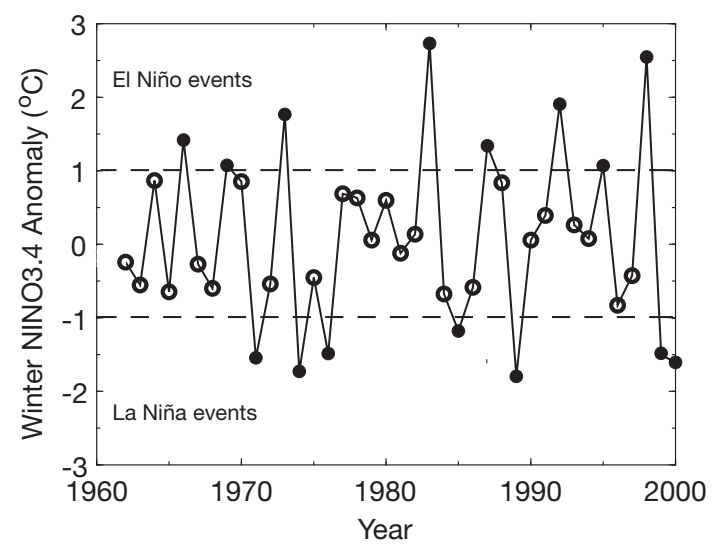

Fig. 5. Mean winter (December-February) NINO3.4 seasurface temperature anomalies, 1962-2000. Values above $1^{\circ}$ indicate El Niño events, and values below $-1{ }^{\circ} \mathrm{C}$ indicate La Niña events

Table 1. Number of observations for each weather type and climate condition

\begin{tabular}{|lrrc|}
\hline & El Niño & Neutral & La Niña \\
\hline CH & 117 & 363 & 94 \\
PH & 19 & 60 & 13 \\
GH & 29 & 53 & 28 \\
CR & 11 & 51 & 17 \\
GR & 44 & 150 & 100 \\
FGR & 39 & 154 & 39 \\
FOR & 188 & 493 & 82 \\
\hline
\end{tabular}

$t$-test) from frequencies for neutral conditions. For La Niña events, GR is much more frequent than during neutral years and FOR weather is much less frequent. These results indicate that the most significant effects of ENSO on weather-type frequencies at New Orleans are effects on GR and FOR weather during La Niña events.

The changes in GR and FOR frequencies for La Niña events suggest a shift in storm track positions over Louisiana. GR weather occurs on the western side of high-pressure systems that are centered to the east of Louisiana, and FOR weather occurs behind cold fronts or ahead of warm fronts. During La Niña conditions the changes in GR and FOR frequencies suggests that storms track farther north than during other years. This effect is illustrated by mean winter $700 \mathrm{hPa}$ height anomalies for El Niño and La Niña events (Fig. 7; Ropelewski \& Halpert 1986, Hoerling et al. 1997, Dettinger et al. 2001). During El Niño winters, $700 \mathrm{hPa}$ height anomalies indicate anomalously low atmos- 

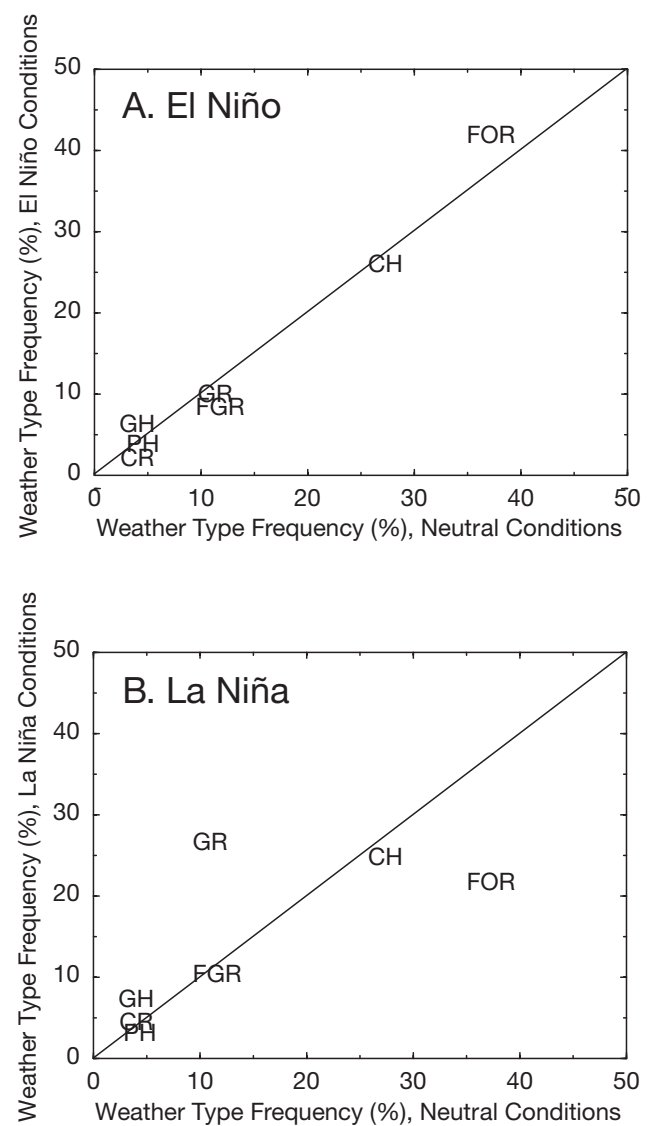

Fig. 6. Comparison of mean winter (December-February) weather-type frequencies for neutral conditions with mean winter weather-type frequencies for (A) El Niño and (B) La Niña events

pheric pressures that extend from the eastern Pacific Ocean across the southern US to the Atlantic Ocean. The negative $700 \mathrm{hPa}$ height anomalies across the southern US reflect the movement of storm systems through this region during El Niño conditions. The southerly displaced storm track results in the more frequent passage of mid-latitude cyclones farther to the south of New Orleans during El Niño conditions than during neutral and La Niña conditions. The southerly displaced location of cyclones results in an increased frequency of FOR weather at New Orleans. The example map of FOR weather in Fig. 1 illustrates FOR weather behind a cold front; however, FOR weather also occurs when warm fronts are to the south of New Orleans. The increase in FOR weather for El Niño conditions and the negative pressure anomalies illustrated in Fig. 7 suggest a southerly displaced storm track and possibly an increase in the frequency of frontal weather to the south of New Orleans. This is supported by an increase $(15 \%)$ in easterly winds and a decrease $(-14 \%)$ in northerly winds during El Niño FOR weather compared with La Niña conditions. These dif- ferences in wind directions suggest an increase in warm-frontal FOR weather and a decrease in coldfrontal FOR conditions during El Niño conditions. Consistent with these results, Douglas \& Englehart (1981) found increased frontal activity in the Gulf of Mexico during El Niño events.

In contrast, for La Niña events, positive $700 \mathrm{hPa}$ heights extend from the eastern Pacific Ocean across the southern US to the Atlantic Ocean. The positive height anomalies across the southern US indicate a decrease in storm frequency and/or intensity. The negative pressure anomalies over Canada suggest increased storm frequency and/or intensity in this region. These anomalies suggest a shift in storm tracks northward during La Niña events. The positive atmospheric pressure anomalies that extend from the Atlantic Ocean across the southeastern US are reflective of the atmospheric patterns associated with CR and GR weather (Fig. 1). These weather types are relatively dry (Fig. 3), and thus increases in the frequency of these weather types result in drier and warmer than average winters.

To examine further the effects of ENSO on storminess, relations between tropical Pacific SSTs and a

\section{A. El Niño}

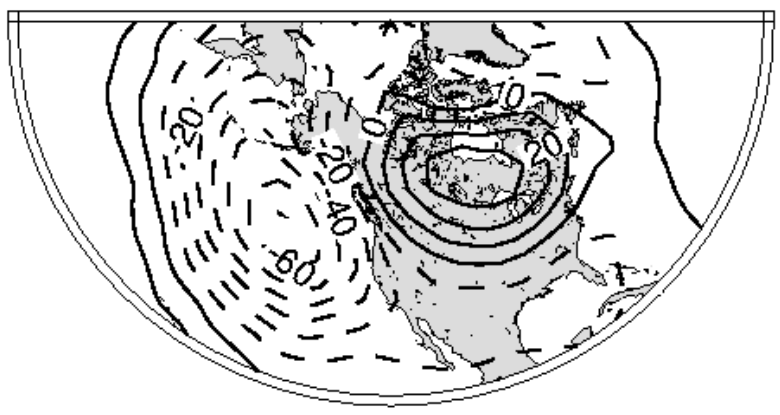

\section{B. La Niña}

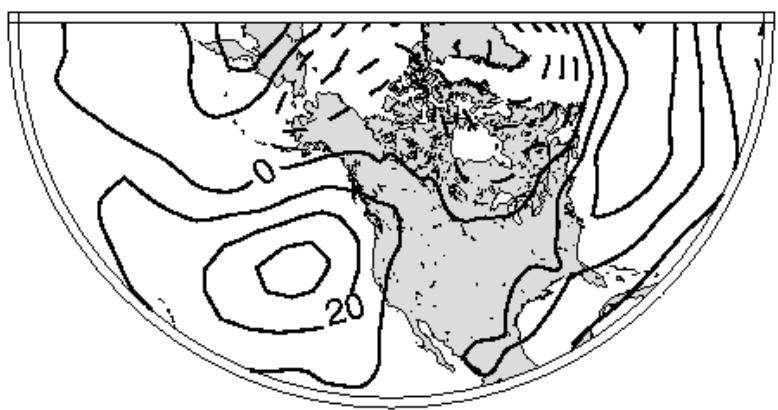

Fig. 7. Mean winter (December-February) $700 \mathrm{hPa}$ height anomalies in meters for (A) El Niño winters and (B) La Niña winters. Solid isolines indicate positive anomalies and dashed lines indicate negative anomalies. The first solid isoline is the zero line, and the contour interval is 20 


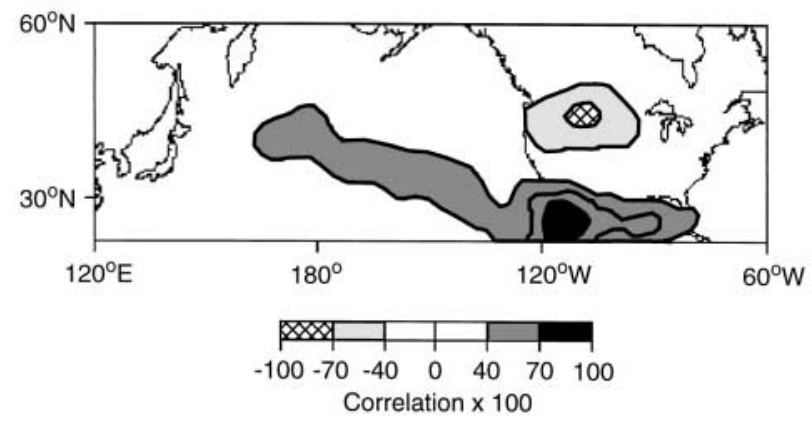

Fig. 8. Correlations $(\times 100)$ between winter (NovemberMarch) NINO3 sea-surface temperatures (SSTs) (SSTs averaged for $5^{\circ} \mathrm{S}-5^{\circ} \mathrm{N}, 90-150^{\circ} \mathrm{W}$ ) and winter $500 \mathrm{hPa}$ storminess (1949-1990). The contour interval is 20 and shaded areas indicate correlations that are significant at a $99 \%$ confidence level (the shading interval is 30 )

storminess index were examined. The storminess index used here was analyzed by Bitz \& Battisti (1999) and Dettinger et al. (2001), and it is a Novemberthrough-March average of the monthly standard deviations of the daily high-frequency ( 2 to $8 \mathrm{~d}$ ) variance of $500 \mathrm{hPa}$ height anomalies (1949-1990). The high-frequency pressure variations registered by this measure correspond to increases and decreases in weather variations associated mostly with the passage of storms. Thus, a comparison of these storminess measures to the Pacific climate variations highlights changes in the average locations of storm tracks during the various phases of ENSO. Correlations between winter storminess and winter tropical Pacific SSTs indicate positive correlations from the tropical Pacific Ocean that extend across the southern US (Fig. 8). These correlations indicate increased storminess across the southern US during El Niño events, and decreased storminess in this region for La Niña events. These results are consistent with the analysis of $700 \mathrm{hPa}$ height anomalies for El Niño and La Niña events (Fig. 7) as well as the decreases (increases) in GR weather and the increases (decreases) in FOR weather for El Niño and La Niña events respectively.

\subsection{Effects on winter temperature and precipitation at New Orleans}

Variability in ENSO (indexed by NINO3.4 SSTs) has a statistically significant effect on winter temperature and especially precipitation observed at New Orleans (Fig. 9A,B). Because the frequencies of GR and FOR weather are sensitive to ENSO, variability in these weather types should also be reflected in winter temperature and precipitation. Comparison of winter GR and FOR weather-type frequencies and winter temper- ature and precipitation indicate statistically significant relations (Fig. 9C-F). GR weather is a warm fair weather type. As the frequency of GR weather increases, temperature increases and precipitation decreases. In contrast, FOR weather is a cold stormy weather type. When FOR frequency increases, temperature decreases and precipitation increases. Thus, for La Niña events, since GR frequency is greater than average and FOR frequency is less than average, winter temperatures should be above average and winter precipitation should be below average. Fig. 9C-F support these conclusions.

Although temperatures at New Orleans during El Niño conditions are generally cooler than average (Fig. 9A), the effects on the temperature properties of individual weather types are small (Fig. 10A,B).

ENSO effects on mean precipitation of individual weather types also are small (Fig. 11A,B) except for GR, FGR, and FOR weather. For El Niño events, precipitation for GR, FGR, and FOR are greater than for neutral conditions (Fig. 11A). However, only the effects on precipitation for GR and FOR weather are statistically significant (at a $95 \%$ confidence level). For La Niña events, the largest effect on weather-type precipitation properties are for FOR weather (this effect is significant at a $95 \%$ confidence level) (Fig. 11B).
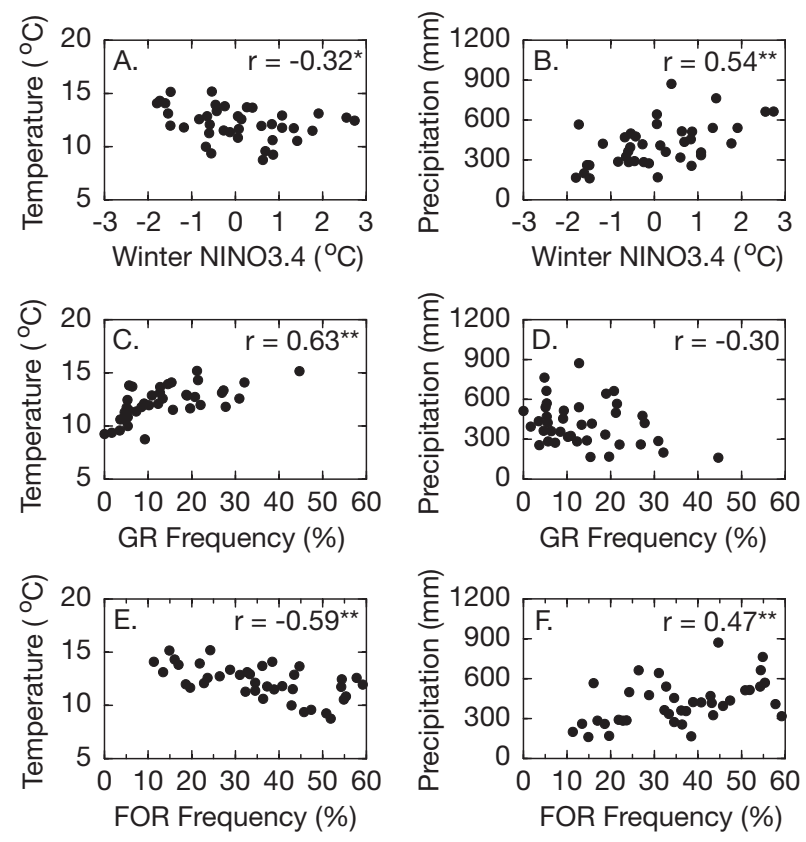

* correlations significant at a 95 percent confidence level

Fig. 9. Comparison of winter (December-February) temperature and precipitation at New Orleans with winter NINO3.4 SSTs, winter GR frequency, and winter FOR frequency, $1962-2000$ 

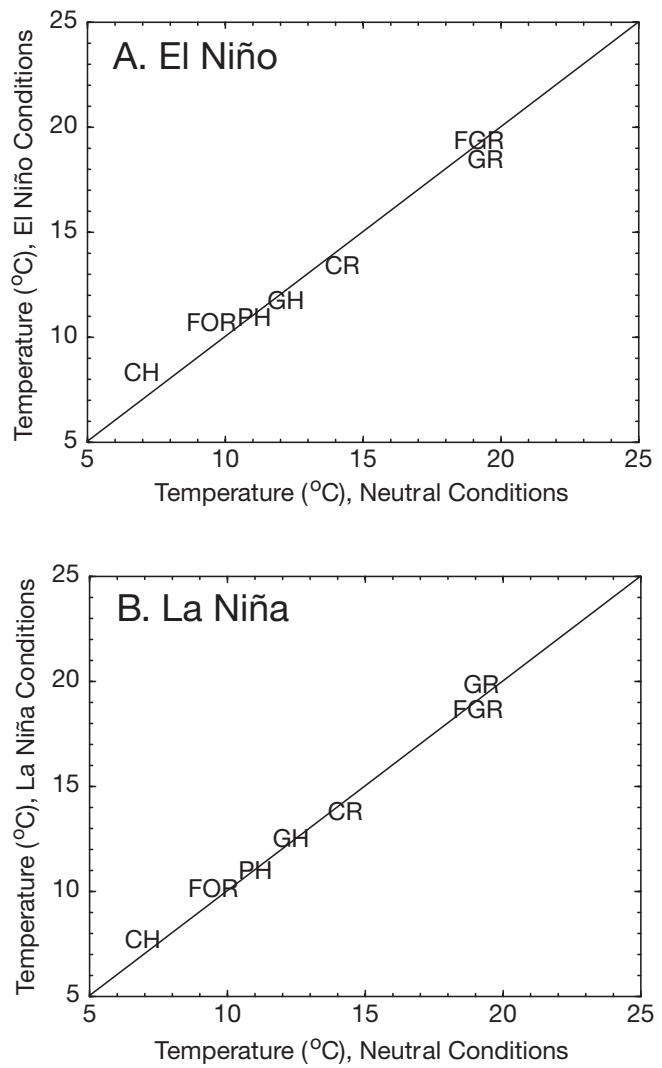

Fig. 10. Comparison of mean winter (December-February) weather-type temperature for neutral conditions with mean winter weather-type temperature for (A) El Niño and (B) La Niña events

Precipitation during El Niño events is enhanced, in part, because of an increase in water vapor transport from the tropics into the Gulf of Mexico region during El Niño events (M. Dettinger, US Geological Survey, Scripps Institution of Oceanography, La Jolla, CA, pers. comm.). The increased vapor transport results in increased moisture content of the atmosphere and increased precipitation.

The increase in mean precipitation for GR, FGR, and FOR weather during El Niño events also can be explained by changes in precipitation characteristics (i.e. mean precipitation rate for days with precipitation and the frequency of precipitation days; Fig. 12). These statistics indicate that mean precipitation rate and the frequency of precipitation days is greatest for El Niño conditions and least for La Niña conditions. These results are consistent for wetter conditions (increased water vapor content of the atmosphere) during El Niño conditions than for neutral and La Niña conditions.

Another factor that could contribute to increased precipitation is increased persistence (mean number of consecutive days per occurrence) of stormy weather types (Fig. 13). An analysis of the mean persistence (in days) of GR, FGR, and FOR weather for El Niño, neutral, and La Niña conditions indicates that differences in persistence are small except for a large increase in GR persistence for El Niño events relative to neutral conditions. The greater persistence of GR weather during El Niño events (relative to neutral conditions) may be a cause of the increase in mean GR precipitation for El Niño conditions. In contrast, for FGR and FOR weather, the persistence of these weather types during El Niño and La Niña events is similar to or less than the persistence during neutral conditions. Thus, persistence does not seem to be related to the increased precipitation for these weather types during El Niño conditions.

\subsection{Comparison of changes in frequency and properties}

Because the analyses indicated significant differences in the frequency and precipitation properties of
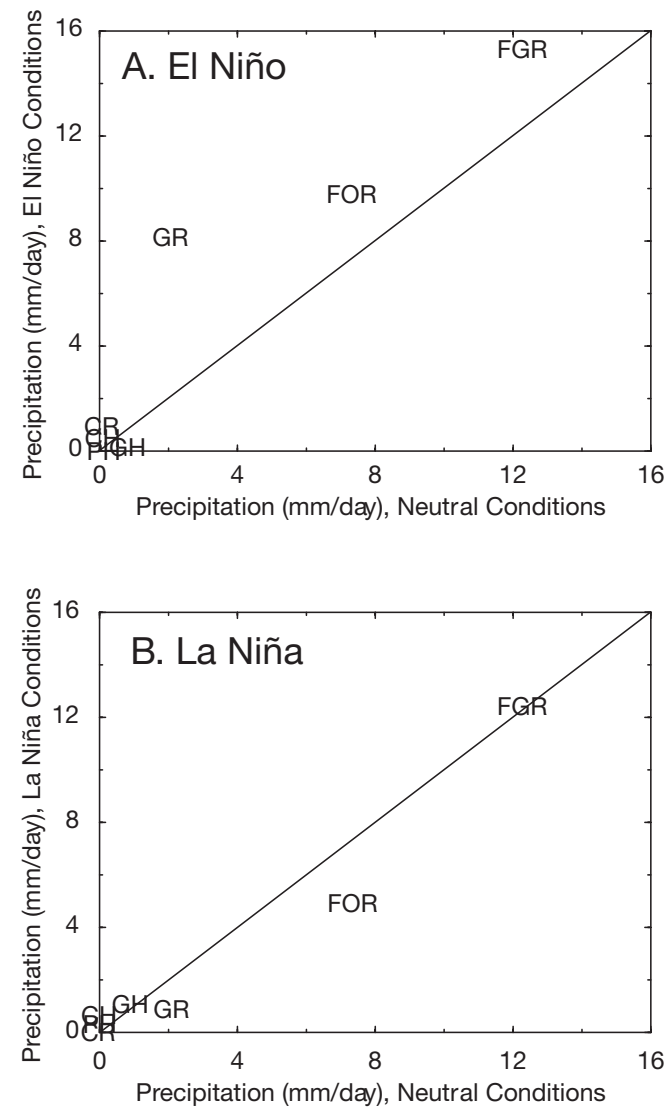

Fig. 11. Comparison of mean winter (December-February) weather-type precipitation for neutral conditions with mean winter weather-type precipitation for (A) El Niño and (B) La Niña events 


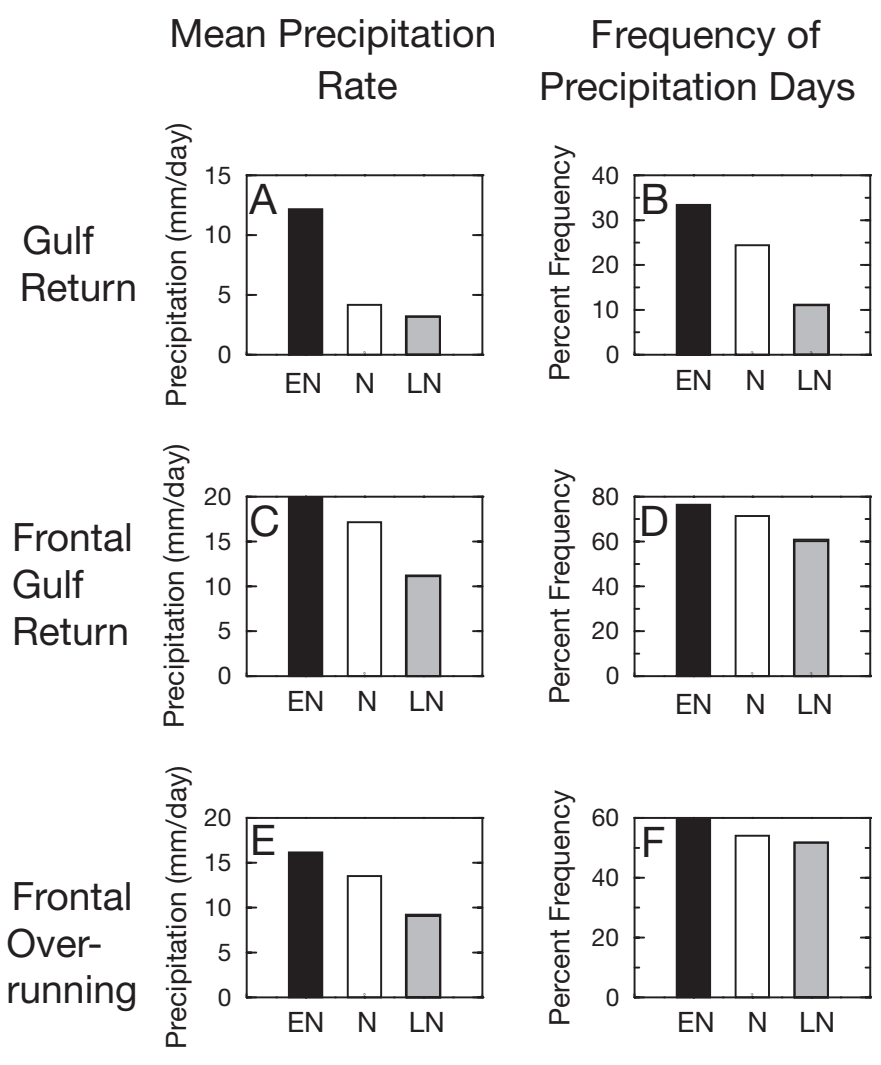

Fig. 12. Winter (December-January) mean precipitation rate for days with precipitation and the frequency of precipitation days for GR, FGR, and FOR weather during El Niño (EN), Neutral (N), and La Niña (LN) conditions, 1962-2000

some of the weather types for El Niño and La Niña conditions, an additional analysis was performed to determine which changes were most significantly correlated with ENSO. This analysis involved the correlation of winter NINO3.4 SST anomalies with time series of winter weather-type frequencies and winter weather-type temperature/precipitation properties (Fig. 14). Results of this analysis indicate that variability in the frequency of only 2 weather types (i.e. GR and FOR) is significantly correlated (at a 95\% confidence level) with NINO3.4 SSTs. Although mean temperature/precipitation properties for some weather types are significantly different from neutral conditions for El Niño and La Niña conditions, the interannual variability in these properties is not well correlated with ENSO. These results suggest that the most significant effect of ENSO on weather types for New Orleans is the effect on the frequency of GR and FOR weather.

Because GR, FGR, and FOR weather indicated significant changes in mean daily precipitation for El Niño conditions, it is surprising that precipitation for these weather types did not result in significant corre- lations with NINO3.4 SSTs. To examine this result further, precipitation characteristics (i.e. precipitation rate for days with precipitation, and the frequency of precipitation days) were examined, instead of mean winter precipitation. Results of this analysis indicated statistically significant correlations (at a 95\% confidence level) between NINO3.4 SSTs and precipitation rate and the frequency of precipitation days for FOR weather (Fig. 15). These results indicate that ENSO has at least a significant effect on precipitation characteristics of FOR weather. The positive correlations between the precipitation rate for FOR weather is consistent with increased vapor transport into the Gulf Coast region during El Niño events, and the increased frequency of precipitation days is consistent with increases in warm-frontal FOR weather as a result of a southerly displaced storm track.

\section{CONCLUSIONS}

Effects of ENSO on winter weather-type frequencies and winter weather-type temperature/

A. Gulf Return

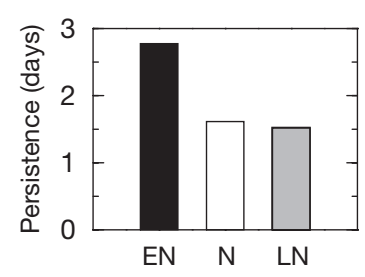

B. Frontal Gulf Return

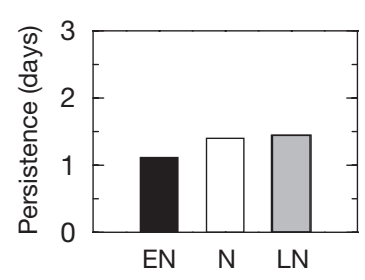

C. Frontal Overrunning

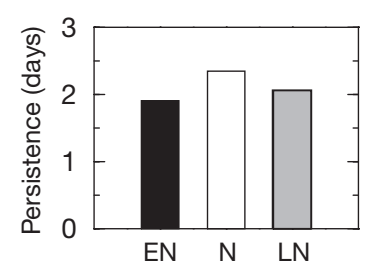

Fig. 13. Winter (December-January) mean persistence of (A) GR, (B) FGR, and (C) FOR weather during El Niño (EN), neutral (N), and La Niña (LN) conditions, 1962-2000 


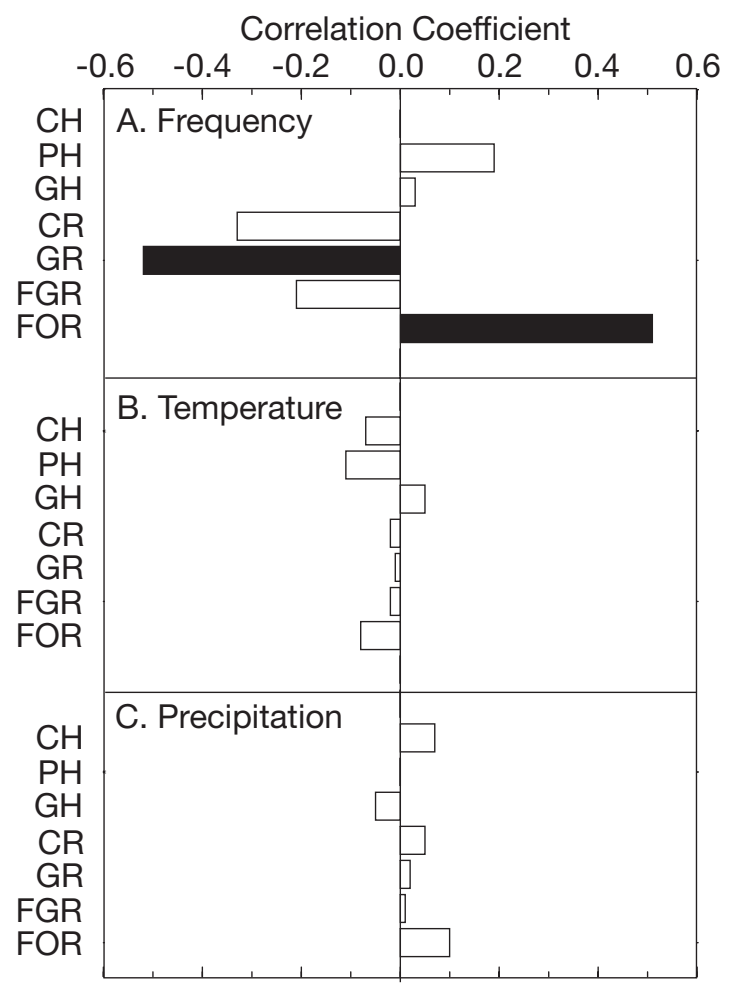

Fig. 14. Correlations between winter (December-February) NINO3.4 and winter weather-type (A) frequencies, (B) temperature, and (C) precipitation, 1962-2000. Solid bars indicate correlations that are significant at a $95 \%$ confidence level

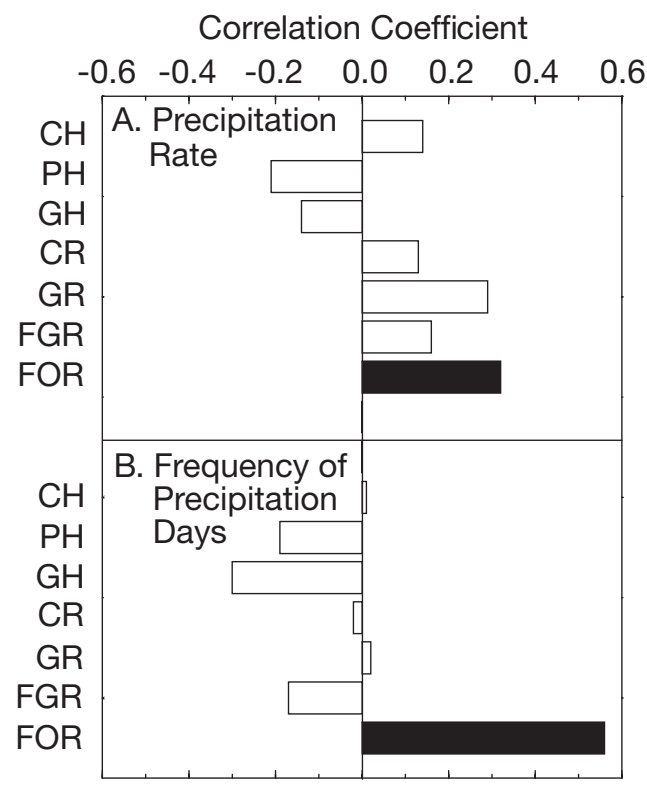

Fig. 15. Correlations between winter (December-February) NINO3.4 and winter weather-type (A) precipitation rate, and (B) frequency of precipitation days, 1962-2000. Solid bars indicate correlations that are significant at a $95 \%$ confidence level precipitation properties were examined using NINO3.4 SSTs as an index of ENSO. For El Niño conditions, winter temperatures at New Orleans are slightly below average and winter precipitation is above average. For La Niña conditions, winter temperatures at New Orleans are warmer than average and winter precipitation is below average. These differences in climatic conditions are related to differences in weather-type frequencies and/or weather-type temperature/precipitation properties.

Effects of ENSO on New Orleans climate are not evident in the temperature properties of weather types, but are seen in the precipitation properties of GR, FGR, and FOR weather. The effects on precipitation properties are greatest for El Niño events, when precipitation for GR, FGR, and FOR weather is greater than for neutral conditions.

Significant effects of ENSO on New Orleans' climate also are reflected by changes in weather-type frequencies. The effects on weather-type frequencies are most significant for GR and FOR weather and are greatest for La Niña Events. For La Niña conditions, GR frequency is greater than that for neutral conditions, and FOR frequency is less than that for neutral conditions. These effects on GR and FOR weather-type frequencies are indicative of a northward shift in storm tracks during La Niña conditions.

The results of the analyses presented in this paper suggest that the effects of ENSO on local New Orleans climate are reflected by (1) increases in precipitation for GR, FGR, and FOR weather during El Niño events, and (2) increases (decreases) in the frequency of GR (FOR) weather during La Niña events.

\section{LITERATURE CITED}

Bitz CM, Battisti DS (1999) Interannual to decadal variability and the glacier mass balance in Washington, Western Canada, and Alaska. J Clim 12:3181-3196

Blalock HM (1979) Social statistics. McGraw-Hill, New York

Conover WJ (1980) Practical nonparametric statistics. John Wiley and Sons, New York

Dettinger MD, Battisti DS, Garreaud RD, McCabe GJ, Bitz CM (2001) Interhemispheric effects of interannual and decadal ENSO-like climate variations on the Americas. In: Markgraf V (ed) Interhemispheric climate linkages. Academic Press, San Diego, p 1-16

Douglas A, Englehart PJ (1981) On a statistical relationship between Autumn rainfall in the central equatorial Pacific and subsequent winter precipitation in Florida. Mon Weather Rev 109:2377-2382

Faiers G (1988) A synoptic weather type analysis of January hourly precipitation at Lake Charles, Louisiana. Phys Geogr 9:223-231

Gershunov A, Barnett TP (1998) Interdecadal modulation of ENSO teleconnections. Bull Am Meteorol Soc 79: $2715-2725$

Hess P, Brezowsky H (1969) Katalog der Grosswetterlagen Europas. Ber Dtsch Wetterdienst 15:113 
Hoerling MP, Kumer A, Zhong M (1997) El Niño, La Niña, and the nonlinearity of their teleconnections. J Clim 10: 1769-1786

Kiladis GN, Diaz HF (1989) Global climatic anomalies associated with extremes of the Southern Oscillation. J Clim 2: 1029-1090

Lamb HH (1972) British Isles weather types and a register of the daily sequence of circulation patterns, 1961-1971. Geogr Mem 116

McCabe GJ, Muller RA (1986) Synoptic weather types: an index of evaporation in southern Louisiana. Phys Geogr 8: 99-112

Muller RA (1977) A synoptic climatology for environmental baseline analysis: New Orleans. J Appl Meteorol 16: 20-32

Muller RA, Wax CL (1977) A comparative synoptic climatic

Editorial responsibility: Andrew Comrie,

Tucson, Arizona, USA baseline for coastal Louisiana. Geosci Man 18:121-129

Ropelewski CF, Halpert MS (1986) North American precipitation and temperature patterns associated with the El Niño/Southern Oscillation (ENSO). Mon Weather Rev 114: 2352-2362

Sittel M (1994) Differences in the means of ENSO extremes for temperature and precipitation in the United States. Centre for Ocean-Atmospheric Prediction Studies (COAPS) Tech Rep 94-2

Trenberth KE (1997) The definition of El Niño. Bull Am Meteorol Soc 78:2771-2777

Trenberth KE, Hoar TJ (1996) The 1990-1995 El Niño-Southern Oscillation event: longest on record. Geophys Res Lett 23:57-60

Yarnal B (1993) Synoptic climatology in environmental analysis. Belhaven Press, London

Submitted: April 15, 2001; Accepted: July 23, 2001

Proofs received from author(s): January 1, 2002 